This item was submitted to Loughborough's Research Repository by the author.

Items in Figshare are protected by copyright, with all rights reserved, unless otherwise indicated.

\title{
Sports drink intake pattern affects exogenous carbohydrate oxidation during running
}

PLEASE CITE THE PUBLISHED VERSION

https://doi.org/10.1249/MSS.0000000000002334

\section{PUBLISHER}

Lippincott, Williams \& Wilkins

\section{VERSION}

AM (Accepted Manuscript)

\section{PUBLISHER STATEMENT}

This is a non-final version of an article published in final form in MEARS, S. ... et al, 2020. Sports drink intake pattern affects exogenous carbohydrate oxidation during running. Medicine and Science in Sports and Exercise, 52 (9), pp.1976-1982, doi: 10.1249/MSS.0000000000002334.

\section{LICENCE}

CC BY-NC-ND 4.0

\section{REPOSITORY RECORD}

Mears, Stephen, Benjamin Boxer, David Sheldon, Hannah Wardley, Caroline A Tarnowski, Lewis James, and Carl Hulston. 2020. "Sports Drink Intake Pattern Affects Exogenous Carbohydrate Oxidation During Running". Loughborough University. https://hdl.handle.net/2134/12046290.v1. 


\section{Title Page}

2 Sports drink intake pattern affects exogenous carbohydrate oxidation during running

3 Stephen A. Mears ${ }^{1}$, Benjamin Boxer ${ }^{1}$, David Sheldon ${ }^{1}$, Hannah Wardley ${ }^{1}$, Caroline A.

4 Tarnowski $^{1}$, Lewis J. James ${ }^{1}$, Carl J. Hulston ${ }^{1}$

$5{ }^{1}$ School of Sport, Exercise and Health Sciences, Loughborough University, Loughborough, $6 \quad \mathrm{UK}$

7

8 Corresponding Author

$9 \quad$ Dr Stephen Mears

10 School of Sport, Exercise and Health Sciences, Loughborough University, Loughborough, 11 LE11 3TU, UK

12 Telephone: +44 1509226391

13 Fax: +44 1509226301

14 Email: s.a.mears@lboro.ac.uk 
Abstract

PURPOSE: To determine whether the pattern of carbohydrate sports drink ingestion during prolonged sub-maximal running affects exogenous carbohydrate oxidation rates and gastrointestinal (GI) comfort.

METHODS: Twelve well-trained male runners $\left(27 \pm 7 \mathrm{y}, 67.9 \pm 6.7 \mathrm{~kg}\right.$, $\mathrm{VO}_{2 \text { peak: }} 68 \pm 7$ $\mathrm{mL} \cdot \mathrm{kg}^{-1} \cdot \mathrm{min}^{-1}$ ) completed two exercise trials of 100 min steady state running at $70 \% \dot{\mathrm{V}} 2$ peak. In each of the trials, $1 \mathrm{~L}$ of a $10 \%$ dextrose solution, enriched with $\left[\mathrm{U}-{ }^{13} \mathrm{C}\right]$ glucose, was consumed as either $200 \mathrm{~mL}$ every $20 \mathrm{~min}(\mathrm{CHO}-20)$ or $50 \mathrm{~mL}$ every $5 \mathrm{~min}$ (CHO-5). Expired breath and venous blood samples were collected at rest and every 20 min during exercise. Subjective scales of GI comfort were recorded at regular intervals.

RESULTS: Average exogenous carbohydrate oxidation rates were $23 \%$ higher during exercise in $\mathrm{CHO}-20\left(0.38 \pm 0.11\right.$ vs. $\left.0.31 \pm 0.11 \mathrm{~g} \cdot \mathrm{min}^{-1} ; P=0.017\right)$. Peak exogenous carbohydrate oxidation was also higher in CHO-20 $\left(0.68 \pm 0.14 \mathrm{~g} \cdot \mathrm{min}^{-1}\right.$ vs. $\left.0.61 \pm 0.14 \mathrm{~g} \cdot \mathrm{min}^{-1} ; P=0.004\right)$. During exercise, total carbohydrate oxidation (CHO-20: $2.15 \pm 0.47$; CHO-5: $2.23 \pm 0.45$ $\left.\mathrm{g} \cdot \mathrm{min}^{-1}, P=0.412\right)$ and endogenous carbohydrate oxidation (CHO-20: $1.78 \pm 0.45$; CHO-5: 1.92 $\left.\pm 0.40 \mathrm{~g} \cdot \mathrm{min}^{-1} ; P=0.148\right)$ were not different between trials. Average serum glucose $(P=0.952)$ and insulin $(P=0.373)$ concentrations were not different between trials. There were no differences in reported symptoms of GI comfort and stomach bloatedness $(P>0.05)$, with only $3 \%$ of reported scores classed as severe $(\geq 5$ out of 10$)$.

CONCLUSION: Ingestion of a larger volume of carbohydrate solution at less frequent intervals during prolonged submaximal running increased exogenous carbohydrate oxidation rates. Neither drinking pattern resulted in increased markers of GI discomfort to a severe level. 
It is well established that carbohydrate ingestion during prolonged sub-maximal exercise increases plasma glucose availability during exercise, contributing to delayed fatigue (1) and enhanced performance (reviewed by (2)). Specific recommendations for carbohydrate ingestion will depend on the duration and intensity of the event. Current recommendations are to consume $30-60 \mathrm{~g} \cdot \mathrm{h}^{-1}$ carbohydrate for events lasting 1-2.5 $\mathrm{h}$ and up to $90 \mathrm{~g} \cdot \mathrm{h}^{-1}$ of multiple sources of carbohydrate for events over $2.5 \mathrm{~h}$ (3). For a rapidly absorbed single source of carbohydrate such as glucose, the maximal rate of exogenous carbohydrate oxidation is approximately $1.0-1.2 \mathrm{~g} \cdot \mathrm{min}^{-1}(4)$. Utilization of exogenous carbohydrate is primarily limited by intestinal absorption $(5,6,7)$ but other limiting factors may include gastric emptying, hepatic glucose extraction, and/ or uptake at the muscle (2).

Exogenous carbohydrate oxidation studies are often conducted using cycling as the mode of exercise. Many of these studies have adopted aggressive ingestion strategies to maximise carbohydrate delivery to the intestines through stimulation of gastric emptying, $(5,6,7,8)$. Typically, a large volume $(400-600 \mathrm{~mL})$ of fluid is provided immediately prior to exercise, with additional large boluses (100-200 mL) ingested at regular intervals (every 10-15 min) during exercise. This has resulted in maximal exogenous carbohydrate oxidation rates $>1.0$ $\mathrm{g} \cdot \mathrm{min}^{-1}$. The frequent ingestion of large volumes of carbohydrate-containing beverages has been well tolerated in laboratory-based cycling experiments. However, such ingestion strategies may not be feasible in the real-world, especially in sports such as running where it is difficult to carry as much fluid as on the bike and where increased risk of gastrointestinal (GI) disturbances may be a consideration for fluid/ carbohydrate intake.

In distance running, the mechanical motion has been linked to increased GI disturbances (9). As such, runners are unlikely to ingest a large pre-race bolus and will typically consume a 
maximum of $\sim 150-200 \mathrm{~mL}$ at drinks stations (positioned every $5 \mathrm{~km}: \sim 15-20 \mathrm{~min}$ ). Recently, elite athletes in major marathon races and record attempts have experimented with ingesting drinks more frequently (every 1-2 km; 2.5-6.0 min), allowing total delivery of a large amount of carbohydrate in relatively small volumes $(\sim 50-100 \mathrm{~mL})$. However, the effect of this revised drinking strategy on exogenous carbohydrate oxidation has not been assessed in runners (or cyclists). Smaller, more frequent volumes of carbohydrate may minimise GI issues, but they also may reduce gastric emptying and limit exogenous carbohydrate oxidation, particularly in situations where a large 'priming' bolus of drink is not ingested immediately before exercise. There are also practical challenges of collecting and then consuming fluid whilst running at high speeds. A large volume may be more difficult to ingest, but frequent consumption of smaller volumes may be inconvenient and make it more difficult to maintain race pace. Therefore, there remains a question surrounding the balance between optimal drink volume and frequency to maximise carbohydrate delivery and utilization, whilst minimizing gastrointestinal disturbances.

The aim of this study was to investigate the effect of drink pattern (volume and frequency) on exogenous carbohydrate oxidation and markers of GI comfort. It was hypothesised that ingestion of less frequent, larger volumes of carbohydrate would increase exogenous carbohydrate oxidation but also increase the prevalence of GI discomfort. 
Twelve well trained male runners and triathletes $\left(27 \pm 7 \mathrm{y}, 67.9 \pm 6.7 \mathrm{~kg}\right.$, $\mathrm{VO}_{2 \text { peak: }} 68 \pm 7$ $\mathrm{mL} \cdot \mathrm{kg}^{-1} \cdot \mathrm{min}^{-1}$ ) participated in this study. Subjects were provided with verbal and written information regarding the study before providing written informed consent and completing a health screen questionnaire. The study was approved by the Loughborough University Ethical Approvals (Human Participants) Sub-Committee. It was estimated that 12 subjects were required to detect a $10 \%$ difference in exogenous carbohydrate oxidation between trials based on a statistical power of 0.8 and an alpha of $0.05(10)$.

Subjects visited the laboratory on 4 occasions: a preliminary peak oxygen uptake $\left(\dot{\mathrm{VO}}_{2 \text { peak }}\right)$ test, a familiarization trial, in which water was ingested at a rate of $200 \mathrm{~mL}$ every $20 \mathrm{~min}$ (this trial also provided a background correction for ${ }^{13} \mathrm{CO}_{2}$ breath enrichment), and two experimental trials in which a $10 \%$ dextrose solution was ingested as either $200 \mathrm{~mL}$ every $20 \mathrm{~min}(\mathrm{CHO}-20)$ or $50 \mathrm{~mL}$ every $5 \mathrm{~min}(\mathrm{CHO}-5)$. The two carbohydrate trials were performed in a counterbalanced cross-over design, separated by $\geq 7 \mathrm{~d}$.

\section{Preliminary testing}

After measuring height and nude body mass (AFW-120K, Adam Equipment Co., UK), subjects performed a $\dot{\mathrm{V}}_{2 \text { peak }}$ test on a motorised treadmill (mercury h/p/cosmos, Nussdorf, Germany). Subjects completed 4 min stages at progressive speeds until a heart rate $>160 \mathrm{~b} \cdot \mathrm{min}^{-1}$ was elicited (measured using Polar M400, Polar, Kemple, Finland). Expired gas was collected into Douglas bags during the final minute of each stage and analysed for oxygen and carbon dioxide concentrations (Servomex 1400 Oxygen and Carbon Dioxide Gas Analyser, Servomex, Crowborough, UK). Gas volume (Harvard dry gas meter, Harvard Apparatus Ltd, Edenbridge, 
measured and corrected to standard temperature and pressure, dry. To correct $\dot{\mathrm{VO}}_{2}$ and $\dot{\mathrm{V} C O}{ }_{2}$ values, ambient air was collected simultaneously with expired gas samples (11). Following a short period of rest ( 10-15 min), subjects ran to volitional exhaustion using a ramped protocol. Set at the speed of the final sub-maximal stage, incline was increased by $1 \%$ each min until volitional exhaustion. An expired gas sample was collected during the final minute of exercise.

Pre-trial standardization

Subjects were asked to record physical activity and dietary intake in the $24 \mathrm{~h}$ before the water trial and were then asked to replicate this before each of the carbohydrate trials. They were also asked to refrain from strenuous exercise in the $24 \mathrm{~h}$ before all trials. In addition, subjects were asked to follow a specific exercise and diet regime designed to reduce the background shift in ${ }^{13} \mathrm{CO}_{2}$ (12). At least 2-4 d prior to each experimental trial, subjects completed an exhaustive bout of exercise (replicated at the same time prior to subsequent trials). This was to oxidise ${ }^{13} \mathrm{C}$ enriched glycogen. Following this, subjects were asked to refrain from eating foods that had a naturally high abundance of ${ }^{13} \mathrm{C}$ including commercially available sports drinks and carbohydrate derived from $\mathrm{C} 4$ plants (e.g. cane sugar and maize). A detailed list of foods to avoid was provided to each subject. Subjects confirmed adherence to all pre-trial standardization requirements before commencing each trial.

\section{Experimental trials}

For each trial, subjects arrived at the laboratory at the same time of day (standardized for each subject between 0600-1000 h) following an overnight fast and 90 min after ingesting $500 \mathrm{~mL}$ water. 
On arrival, subjects provided a urine sample and had nude body mass measured. A 20-gauge

Teflon cannula was then inserted into an antecubital vein of one arm to allow repeated blood $\mathrm{mL}$ evacuated glass tubes (Exetainers, Labco, Ceredigion, UK) for determination of ${ }^{13} \mathrm{CO}_{2}$ enrichment, followed by a 5-min collection of expired gas (analysed for oxygen and carbon dioxide content and gas volume and temperature as described for the preliminary testing). A $5.5 \mathrm{~mL}$ venous blood sample was then collected and heart rate was recorded. Subjects were asked to rate feelings of thirst, GI comfort and stomach bloatedness using scales $(0=$ no feeling, $10=$ extreme feeling). As used in similar studies (13), responses $\geq 5$ were classed as severe, with values $<5$ classed as non-severe.

Immediately prior to the start of exercise, subjects consumed the first drink. They then completed 100 min running at $70 \% \dot{\mathrm{V}} \mathrm{O}_{2 \text { peak }}\left(13.1 \pm 1.0 \mathrm{~km} \cdot \mathrm{h}^{-1}\right)$. A sample period occurred every $20 \mathrm{~min}$ : at $18 \mathrm{~min}$, expired breath samples were collected into exetainers, a $60 \mathrm{~s}$ expired gas collection occurred at $19 \mathrm{~min}$, with heart rate and rating of perceived exertion (RPE) recorded during this collection. At $20 \mathrm{~min}$, subjects straddled the treadmill for $90 \mathrm{~s}$ and a 5.5 $\mathrm{mL}$ blood sample was taken. Once running had recommenced, the next drink was ingested. This was repeated every 20 min. Additional drinks were ingested in CHO-5 at 5 min intervals, with final drinks consumed at $80 \mathrm{~min}$ (water and CHO-20) and $95 \min (\mathrm{CHO}-5)$. Heart rate, RPE and subjective scales of thirst, GI comfort and stomach bloatedness were measured every $10 \mathrm{~min}$, with all scales measured on completion of exercise. Air flow provided by a $0.5 \mathrm{~m}$ diameter fan was placed on the floor and angled at the chest to provide similar air flow in both trials $\left(\sim 3.0-3.5 \mathrm{~m} \cdot \mathrm{s}^{-1}\right)$. After the completion of exercise, subjects towel dried to remove unevaporated sweat and had nude body mass measured. 
149 For each carbohydrate trial, $137.5 \mathrm{~g}$ of glucose (D-glucose monohydrate, MyProtein, 150 Northwich, UK) was measured and then made up to a volume of $1250 \mathrm{~mL}$ to produce a $10 \%$ 151 carbohydrate solution. To account for the different molecular masses of glucose and dextrose 152 monohydrate, the amount of glucose was multiplied by 1.1. The glucose had a low natural 153 abundance of ${ }^{13} \mathrm{C}(-27.22 \delta \%$ vs. Pee Dee Bellemnitella (PDB)), therefore drinks were enriched 154 with uniformly labelled ${ }^{13} \mathrm{C}$ glucose $\left(\sim 0.100 \mathrm{~g}\left[\mathrm{U}-{ }^{13} \mathrm{C}\right]\right.$ glucose $\cdot \mathrm{L}^{-1}$, Cambridge Isotopes 155 Laboratory Inc., Andover, MA, USA). A total of $1.0 \mathrm{~L}$ of each drink, with ${ }^{13} \mathrm{C}$ mean glucose enrichment of $62.5 \pm 3.7 \delta \%$ vs. $\mathrm{PDB}$, was ingested during each trial to provide an average ingestion rate of $1.0 \mathrm{~g} \cdot \mathrm{min}^{-1}$.

Analysis

For each $5.5 \mathrm{~mL}$ of venous blood, $1.0 \mathrm{~mL}$ was aliquoted into a tube containing anticoagulant for analysis of hemoglobin (Cyanmethemoglobin method: Sigma, St Louis, MO, USA) and hematocrit (micro-centrifugation: Hawksley, Worthing, UK). Plasma volume changes were calculated from hemoglobin and hematocrit values (14). The remaining blood was allowed to clot at room temperature before centrifugation at $2200 \mathrm{x} g$ for $15 \mathrm{~min}$ at $4{ }^{\circ} \mathrm{C}$. The serum was removed and frozen at $-20^{\circ} \mathrm{C}$ until later analysis of glucose (spectrophotometry, ABX Pentra 400; Horiba Medical, Northampton, UK) and insulin concentration (enzyme immunoassay, DRG Instruments GmbH, Marburg, Germany). Urine was immediately analysed for osmolality (refractometry, Osmocheck; Vitech Scientific, Horsham, UK).

Breath (gas chromatography isotope ratio mass spectrometry, Hydra 20-20 IRMS; Europa Scientific, Crewe, UK) and drink (elemental analyser isotope ratio mass spectrometry, 20-20 IRMS; Europa Scientific, Crewe, UK) samples were analysed for ${ }^{13} \mathrm{C} /{ }^{12} \mathrm{C}$ ratio (both IsoAnalytical Ltd., Crewe, UK).

Calculations 
173 Stochiometric equations were used to calculate rates of total carbohydrate and fat oxidation

174 (15), with the assumption that oxidation of protein was negligible:

175 Carbohydrate oxidation $\left(\mathrm{g} \cdot \mathrm{min}^{-1}\right)=4.210 \dot{\mathrm{V}} \mathrm{CO}_{2}-2.962 \dot{\mathrm{V}} \mathrm{O}_{2}$

176 Fat oxidation $\left(\mathrm{g} \cdot \mathrm{min}^{-1}\right)=1.695 \dot{\mathrm{VO}}_{2}-1.701 \dot{\mathrm{V}} \mathrm{VO}_{2}$

177 For each expired breath sample, the isotopic enrichment was expressed as $\delta$ per $\mathrm{mL}$ difference 178 between ${ }^{13} \mathrm{C} /{ }^{12} \mathrm{C}$ ratio of the sample and a known laboratory reference standard. The formula 179 (16) used was:

$$
\delta^{13} \mathrm{C}=\left[\left(\frac{{ }^{13} \mathrm{C} /{ }^{12} \mathrm{C} \text { sample }}{{ }^{13} \mathrm{C} /{ }^{12} \mathrm{C} \text { standard }}\right)-1\right] \times 10^{3} \text { per mil }
$$

181 Following this, $\delta^{13} \mathrm{C}$ was then related to the international standard Vienna PDB.

Exogenous carbohydrate oxidation rates were calculated by:

$$
\text { exogenous carbohydrate oxidation }\left(\mathrm{g} \cdot \mathrm{min}^{-1}\right)=\dot{\mathrm{V}} \mathrm{CO}_{2}\left(\frac{\delta \operatorname{Exp}-\operatorname{Exp}_{\mathrm{bkg}}}{\delta \operatorname{Ing}-\operatorname{Exp}_{\mathrm{bkg}}}\right)\left(\frac{1}{k}\right)
$$

where $\delta$ Exp is the ${ }^{13} \mathrm{C}$ expired breath enrichment, $\delta$ Ing is the ${ }^{13} \mathrm{C}$ enrichment of the ingested beverage, $\delta$ Exp $_{\text {bkg }}$ is the ${ }^{13} \mathrm{C}$ expired breath enrichment of the water trial (background), $k$ is the $\mathrm{CO}_{2}$ volume that is produced by oxidation of $1 \mathrm{~g}$ of glucose $(k=0.7467 \mathrm{~L})$.

187 When calculating exogenous carbohydrate oxidation rates using ${ }^{13} \mathrm{CO}_{2}$ from expired gas, a methodological consideration is the ${ }^{13} \mathrm{CO}_{2}$ trapped in the bicarbonate pool. During the onset of exercise, some $\mathrm{CO}_{2}$ arising from the oxidation of glucose will be retained (17), however $\dot{\mathrm{VCO}}_{2}$ will increase during exercise until a condition of physiological steady-state occurs resulting in equilibration between the ${ }^{13} \mathrm{CO}_{2}$ in expired gas and the $\mathrm{CO}_{2} / \mathrm{HCO}_{3}$ pool. Recovery of ${ }^{13} \mathrm{CO}_{2}$ from oxidation of enriched glucose will approach 100\% after approximately $60 \mathrm{~min}(18)$. 
193 Therefore, there is likely to be some underestimation of exogenous carbohydrate oxidation 194 rates during the first $60 \mathrm{~min}$. Data should be interpreted as the minimum estimates.

195 Statistical Analysis

196 Data were checked for normality of distribution using Shapiro-Wilks tests. All data with one 197 factor (urine osmolality, sweat losses, body mass) were normally distributed and analysed 198 using a one-way ANOVA. All data with two factors except thirst and GI measures were 199 normally distributed. Data with two factors (variables measured over time in each trial) were 200 measured using a two-way repeated measures ANOVA. When a significant two-way ANOVA 201 was observed, a paired samples t-test with Holm-Bonferroni correction was performed to 202 identify where the difference occurred. Statistical significance was accepted when $P \leq 0.05$. Data were presented as mean \pm SD. All statistical analysis was conducted using Statistical 204 Package for the Social Sciences for Windows (version 23.0; SPSS, Chicago, IL, USA). 
Baseline measures and pre-trial standardization

Body mass (CHO-20: $67.5 \pm 6.5$, CHO-5: $67.4 \pm 6.5 \mathrm{~kg}$; $P=0.384)$ and urine osmolality (CHO20: $319 \pm 193$, CHO-5: $398 \pm 265 \mathrm{mOsmol} \cdot \mathrm{kg}^{-1} \mathrm{H}_{2} \mathrm{O} ; P=0.076$ ) were not different between trials, providing a good indication that subjects arrived at the laboratory in a similar state of hydration.

211 Resting values of ${ }^{13} \mathrm{C}$ breath enrichment were not different between water and $\mathrm{CHO}$ trials (WAT: $-27.14 \pm 0.32 \delta \%$ vs. PDB, CHO-20: $-27.27 \pm 0.38 \delta \%$ vs. PDB, CHO-5: $-27.18 \pm$ $0.34 \delta \%$ vs. PDB; $P=0.635)$.

Mean $\dot{\mathrm{VO}}_{2}, \dot{\mathrm{V} C O}{ }_{2}$ and RER during exercise were not different between trials (table 1). Exogenous carbohydrate oxidation rates were greater in $\mathrm{CHO}-20$ than $\mathrm{CHO}-5$. This effect was observed both early (20-60 $\mathrm{min})$ and late $(60-100 \mathrm{~min})$ in exercise, with average exogenous carbohydrate oxidation rates across the whole exercise period being $23 \%$ higher in $\mathrm{CHO}-20$ than CHO-5 (table 1). There was also a time $\mathrm{x}$ trial interaction effect for exogenous carbohydrate oxidation and post-hoc analysis detected this at the 100 min timepoint (CHO-20: $0.68 \pm 0.14 \mathrm{~g} \cdot \mathrm{min}^{-1}, \mathrm{CHO}-5: 0.61 \pm 0.14 \mathrm{~g} \cdot \mathrm{min}^{-1}$; figure $\left.1 \mathrm{a}\right)$. These values represent the peak exogenous carbohydrate oxidation rates for each trial. Exogenous carbohydrate oxidation efficiency was a minimum estimate of $38 \%$ in $\mathrm{CHO}-20$ compared to $31 \%$ in $\mathrm{CHO}-5$. Total carbohydrate oxidation and average endogenous carbohydrate oxidation rates during exercise were not different between trials (table 1). There was a significant time $\mathrm{x}$ trial interaction effect $(P=0.041)$ for endogenous carbohydrate oxidation rates, but after correction for multiple comparisons, no post-hoc differences were detected. During exercise, mean fat oxidation was not different between trials (table 1). 
Venous blood data was collected in 11 out of 12 subjects due to sampling problems in one trial and therefore presented accordingly. In both carbohydrate trials, serum glucose concentrations increased from baseline following drink ingestion (time effect: $P<0.0001$, figure 2a). There was no trial $(P=0.938)$ or time $\mathrm{x}$ trial interaction effect $(P=0.095)$. Serum insulin concentrations (figure $2 b$ ) were not different between trials (mean value during exercise, CHO-20: $42.9 \pm 21.5$ $\left.\mathrm{pmol} \cdot \mathrm{L}^{-1}, \mathrm{CHO}-5: 38.2 \pm 16.2 \mathrm{pmol} \cdot \mathrm{L}^{-1}, P=0.373\right)$.

Following the onset of exercise, plasma volume decreased from resting values in both trials (approximately -10.0 to $-12.5 \%$ decrease from baseline; time effect, $P=0.020$, figure 3 ). The pattern of drink ingestion did not influence changes in plasma volume (time $\mathrm{x}$ trial interaction effect, $P=0.425)$.

Heart rate increased progressively throughout exercise and was not different between trials, with mean exercise values of $155 \pm 13 \mathrm{~b} \cdot \mathrm{min}^{-1}$ and $157 \pm 13 \mathrm{~b} \cdot \mathrm{min}^{-1}$ for CHO-20 and CHO-5 trials respectively $(P=0.310)$. Mean RPE values were not different between trials (CHO-20: 11 \pm , CHO-5: $11 \pm 2 ; P=0.723)$. Sweat losses during (CHO-20: $2.04 \pm 0.34 \mathrm{~L}, \mathrm{CHO}-5: 2.09 \pm$ $0.40 \mathrm{~L}, P=0.416)$ and percentage body mass loss at the end (CHO-20: $1.52 \pm 0.40 \%, \mathrm{CHO}-5$ : $1.59 \pm 0.44 \%, P=0.385)$ of exercise were not different between trials. Mean subjective feelings for thirst (CHO-20: $1 \pm 1, \mathrm{CHO}-5: 1 \pm 1$; trial effect: $P=0.836)$, GI comfort $(\mathrm{CHO}-20: 2 \pm 1$, CHO-5: $2 \pm 1$; trial effect: $P=0.830)$ and stomach bloatedness (CHO-20: $2 \pm 1, \mathrm{CHO}-5: 2 \pm 1$; trial effect: $P=0.880$ ) were during both trials. There were no time $\mathrm{x}$ trial interaction effects (thirst: $P=0.682$, GI comfort: $P=0.313$, stomach bloatedness: $P=0.126$ ). Subjective feelings of GI discomfort and stomach bloatedness gradually increased over the course of the exercise period (time effect: $P<0.0001$, figure 4). For GI comfort, four subjects reported a score of 5 in both trials, with a further subject reporting a score of 5 in the $\mathrm{CHO}-20$ trial. Two subjects reported a score of 6 at single timepoints in CHO-5. For reported measures of stomach 
253 bloatedness, 3 subjects reported a score of 5 in both trials, with a further subject reporting a 254 score of 5 in CHO-5. 
The aim of the study was to examine the effect of different drinking patterns (frequency and

257

volume) on exogenous carbohydrate oxidation and gastrointestinal comfort during prolonged submaximal running. The main finding was that consuming larger volumes at less frequent intervals (200 mL every $20 \mathrm{~min}$ ) increased exogenous carbohydrate oxidation compared to consuming smaller volumes at more frequent intervals ( $50 \mathrm{~mL}$ every $5 \mathrm{~min}$ ). In addition, both drinking strategies were well-tolerated and there was no difference in the reported level of GI comfort between trials.

Average exogenous carbohydrate oxidation during exercise was $23 \%$ higher in $\mathrm{CHO}-20$ than in $\mathrm{CHO}-5$, which, given the same amount of carbohydrate was ingested, is a possibly important result, that may have beneficial implications in a performance situation. Over the course of the trials, mean fluid delivery was the same (200 $\mathrm{mL}$ per $20 \mathrm{~min})$, but the larger boluses provided in CHO-20 at the start and throughout exercise likely increased gastric pressure, resulting in increased gastric emptying $(19,20)$. As fluid enters the stomach, there is increased pressure on the antral region, which will contribute to an increased emptying rate (21). Increased gastric contents and pressure will stimulate stretch receptors in the gastric mucosa, therefore increasing the rate of gastric emptying (22,23). Costill and Saltin (20) examined progressively larger volumes of fluid than the initial boluses in the present study and found increased gastric emptying up to $600 \mathrm{~mL}$. It was therefore likely that neither of the initial boluses in the present study were large enough to maximise carbohydrate delivery to the intestines, providing a partial explanation for the relatively low exogenous oxidation rates as well as the failure to observe a plateau. The findings by Costill and Saltin (20) were conducted at rest, and whilst they provide an indication of the role of drink volume in gastric emptying there must also be consideration for other factors, such as exercise intensity, carbohydrate concentration and dehydration. 
279 Peak rates of exogenous carbohydrate oxidation were comparable with studies providing similar amounts of carbohydrate during exercise that either included (24) or did not include $(10,25,26,27)$ a bolus of carbohydrate prior to exercise. Whilst exogenous oxidation rates were similar in Hulston et al. (24), there was a marked difference in oxidation efficiency $(63 \%)$ compared to the present study (minimum estimate of at least 38\% in CHO-20 and 31\% in CHO5). Despite delivery of slightly less carbohydrate during exercise $\left(0.8 \mathrm{~g} \cdot \mathrm{min}^{-1}\right)$ in Hulston et al. (24), this increased efficency is likely driven by the provision of a large, $600 \mathrm{~mL}$ bolus of carbohydrate ( $6 \%$ glucose solution) prior to exercise. It also appears, from other studies, that in order to achieve maximal exogenous oxidation rates of $1.0-1.2 \mathrm{~g} \cdot \mathrm{min}^{-1}$, both a pre-exercise bolus of carbohydrate is required as well as a much larger amount of carbohydrate ingestion during exercise $(5,6,7,8)$, however, particuarly in runners, this combination may exacerbate GI distress. As exogenous oxidation rates were still increasing at $100 \mathrm{~min}$, there are potential improvements to both strategies used in this study, but this must be balanced against the practicalities of the exercise. Whilst mode of exercise has shown similar exogenous carbohydrate oxidation rates between running and cycling (28), exogenous carbohydrate oxidation rates in the present study may have been affected by using runners with limited experience of carbohydrate ingestion during exercise (four subjects had completed at least one marathon and had used carbohydrate in the build-up and during the race but, along with the other subjects were not regular users of carbohydrate during typical training). Running has rates (29).

Markers of GI discomfort progressively increased throughout exercise in both conditions, however there was no difference between drinking pattern and only $3 \%$ of timepoints could be considered as severe ( $\geq 5$ out of 10 ). GI issues can be increased by a greater volume and/ or an 
increase in the carbohydrate concentration/ osmolality of the beverage (30). When large volumes of carbohydrate drinks have been ingested less frequently, an increase in GI discomfort has been reported (31), however, in the low frequency group, drink ingestion was every $60 \mathrm{~min}$ in a far greater volume $(\sim 690 \mathrm{~mL})$ than the current study. The high frequency, small volume pattern used in the study by Stocks et al. (31) was more closely related to the CHO-20 condition with similar GI responses reported.

The intensity used in the present study was $70 \% \dot{\mathrm{VO}}_{2 \text { peak }}$ which is comparable with several other studies $(5,6,24,32,33,34,35)$. At this intensity there is a high reliance on carbohydrate oxidation (36) and, depending on the ingestion strategy, it is possible to achieve peak oxidation rates of $\sim 0.9-1.0 \mathrm{~g} \cdot \mathrm{min}^{-1}(5,32)$. It is also an intensity that can be sustained for exercise durations/ race distances over which carbohydrate ingestion is known to be beneficial to performance. Whilst elite marathon runners will race at even higher intensities $(\sim 75-85 \%$ $\left.\dot{\mathrm{V}}{ }_{2 m a x} ;(37)\right)$, this may not be achievable for sub-elite and recreational runners, especially when performing on a treadmill. Therefore, we selected an exercise intensity and duration that was both achievable for our subjects and that could provide translational results for competitive running races. There does, however, need to be further investigation into the effect of drinking pattern at an increased intensity, as more severe GI symptoms may be reported. The potential increases in symptoms may be exacerbated by decreased gastric emptying rates above $75 \%$ $\dot{\mathrm{V}} \mathrm{O}_{2 \max }(38)$ and/ or the increased mechanical stress placed on the GI system when running at these increased velocities (39). Additionally, at an increased pace, the process of drinking a large volume may be hindered due to increased speed and breathing frequency.

Further work is needed to investigate the impact of drinking pattern on performance. Whilst this study was able to demonstrate a metabolic advantage with $\mathrm{CHO}-20$, there is no guarantee that this will directly translate to improved performance, as there must also be consideration for factors such as the non-oxidative roles of carbohydrate. The effect of carbohydrate sensing 
in the mouth on performance should be also be considered (3) as more frequent sensations of carbohydrate by the central nervous system may be more advantageous. In addition, from a practical perspective, there should be consideration of the opportunity to drink during a race setting as well as the time saved when drinks are consumed less frequently. Whilst a treadmill setting allows greater measurements to improve mechanistic understanding, there is reduced ecological validity in terms of recreating race practicalities. The design of the current study restricts comparison to one of two distinct drinking strategies, whereas in practice athletes are free to consume different volumes as they see fit. It may be that the preferential strategy is to combine both approaches by ingesting a larger volume at the start and during the early part of the race, thereby priming the system, before switching to a smaller volume as the race progresses.

A limitation of the study was that the glycogen depleting exercise was not supervised, whilst it is also preferential to provide a standardised dietary intake (40) rather than just providing guidance and ask subjects to repeat their intake. However, the use of well-motivated subjects, pre-trial interviews confirming diet and depletion exercise and the minimal shift in expired ${ }^{13} \mathrm{C}$ during the water trial were indicative of good adherence to pre-trial standardization procedures.

\section{Conclusion}

In conclusion, drinking a larger volume of a single source of carbohydrate (glucose) every 20 min increased exogenous carbohydrate oxidation compared to the same volume of fluid ingested in smaller volumes every $5 \mathrm{~min}$. At this intensity there was no difference in reported GI issues and neither pattern induced prolonged severe symptoms. However, further work is warranted to investigate the effect of increasing intensity and also, how drinking pattern may affect performance. 
353 The authors acknowledge the work of Marianna Apicella and Kelsie Johnson in assisting with 354 data collection.

\section{Conflict of Interest}

356 No external funding was obtained for the current study. The results of the present study do not 357 constitute endorsement by the American College of Sports Medicine. The results of the study 358 are presented clearly, honestly, and without fabrication, falsification, or inappropriate data 359 manipulation. LJJ has previously received funding from PepsiCo Inc. and Volac International, 360 performed consultancy for PepsiCo Inc. and Lucozade, Ribena Suntory and received 361 conference fees from PepsiCo Inc. and Danone Nutricia. In all cases, monies have always been 362 paid to LJJs institution and not directly to LJJ. 


\section{References}

1. Coyle EF, Coggan AR, Hemmert MK, Ivy JL. Muscle glycogen utilization during prolonged strenuous exercise when fed carbohydrate. $J$ Appl Physiol. 1986;61(1):165-72.

2. Jeukendrup AE. Carbohydrate Intake During Exercise and Performance. Nutrition. 2004;20:669-77.

3. Jeukendrup AE. Nutrition for endurance sports: Marathon, triathlon, and road cycling. $J$ Sports Sci. 2011;29(S1):S91-9.

4. Jeukendrup AE. Jentjens R. Oxidation of Carbohydrate Feedings During Prolonged Exercise. Sports Med. 2000;29(6):407-24.

5. Hawley JA. Dennis SC, Nowitz A, Brouns F, Noakes TD. Exogenous carbohydrate oxidation from maltose and glucose ingested during prolonged exercise. Eur $J$ Appl Physiol. 1992;64:523-7.

6. Jentjens RLPG, Moseley L, Waring RH, Harding LK, Jeukendrup AE. Oxidation of combined ingestion of glucose and fructose during exercise. J Appl Physiol. 2004;96:127784.

7. Jentjens RLPG, Jeukendrup AE. High rates of exogenous carbohydrate oxidation from a mixture of glucose and fructose ingested during prolonged cycling exercise. Br J Nutr. 2005;93(4):485-92.

8. Jeukendrup AE, Wagenmakers AJM, Stegen J, Gijsen AP, Brouns F, Saris WHM. Carbohydrate ingestion can completely suppress endogenous glucose production during exercise. Am J Physiol - Endocrin Metab. 1999;276(4):E672-83.

9. Peters HPF, Wiersma JWC, Koerselman J et al. The Effect of a Sports Drink on Gastroesophageal Reflux During a Run-Bike-Run Test. Int J Sports Med. 1999;20:65-70. 

exogenous carbohydrate during prolonged exercise in fed and fasted conditions. Int J Sports Med. 1990;11(4):253-8.

11. Betts JA, Thompson D. Thinking outside the bag (not necessarily outside the lab). Med Sci Sports Exerc. 2012;44(10):2040.

12. Wagenmakers AJM, Rehrer NJ, Brouns F, Saris WHM, Halliday D. Breath ${ }^{13} \mathrm{CO}_{2}$ and America. J Appl Physiol. 1993;74(5):2253-7.

13. Jeukendrup AE, Vet-Joop K, Sturk A et al. Relationship between gastro-intestinal complaints and endotoxemia, cytokine release and the acute-phase reaction during and after a long-distance triathlon in highly trained men. Clin Sci. 2000;98:47-55.

14. Dill DB, Costill DL. Calculation of percentage changes in volumes of blood, plasma, and red-cells in dehydration. J Appl Physiol. 1974;37:247-8.

15. Jeukendrup AE, Wallis GA. Measurement of substrate oxidation during exercise by means of gas exchange measurements. Int J Sports Med. 2005;26:S28-37.

16. Craig H. Isotopic standards for carbon and oxygen and correction factors. Geochim Comochim Acta. 1957;12:133-49.

17. Robert JJ, Koziet J, Chauvet D, Darmaun D, Desjeux JF, Young VR. Use of ${ }^{13} \mathrm{C}-$ labelled glucose for estimating glucose oxidation: some design considerations. $J$ Appl Physiol. 1987;63(5):1725-32.

18. Pallikarakis N, Sphiris N, Lefèbvre P. Influence of the bicarbonate pool and on the occurrence of ${ }^{13} \mathrm{CO}_{2}$ in exhaled air. Eur J Appl Physiol. 1991;63:179-83. 

gastric emptying and gastrointestinal distress while running. Med Sci Sports Exerc. 1990;22(6):790-5.

20. Costill DL, Saltin B. Factors limiting gastric emptying during rest and exercise. J Appl Physiol. 1974;37(5):679-83.

21. Strunz UT, Grossman MI. Effect of intragastric pressure on gastric emptying and secretion. Am J Physiol. 1978;235(5):E552-5.

22. Minami H, McCallum RW. The Physiology and Pathophysiology of Gastric Emptying in Humans. Gastroenterology. 1984;86:1592-610.

23. Noakes TD, Rehrer NJ, Maughan RJ. The importance of volume in regulating gastric emptying. Med Sci Sports Exerc. 1991;23(3):307-13.

24. Hulston CJ, Wallis GA, Jeukendrup AE. Exogenous CHO oxidation with Glucose Plus Fructose Intake during Exercise. Med Sci Sports Exerc. 2009;41(2):357-63.

25. Burelle Y, Péronnet F, Charpentier S, Lavoie C, Hillaire-Marcel C, Massicotte D. Oxidation of an oral $\left[{ }^{13} \mathrm{C}\right]$ glucose load at rest and prolonged exercise in trained and sedentary subjects. J Appl Physiol. 1999;86(1):52-60.

26. Massicotte D, Péronnet F, Brisson G, Bakkouch K, Hillaire-Marcel C. Oxidation of a glucose polymer during exercise: comparison with glucose and fructose. J Appl Physiol. exogenous carbohydrate during prolonged exercise: the effects of the carbohydrate type and its concentration. Eur J Appl Physiol Occ Physiol. 1992;64(4):328-34. 
28. Pfeiffer B, Stellingwerff T, Zaltas E, Hodgson AB, Jeukendrup AE. Carbohydrate Oxidation from a Drink during Running Compared with Cycling Exercise. Med Sci Sports Exerc. 2011;43(2):327-34.

29. Cox GR, Clark SA, Cox AJ et al. Daily training with high carbohydrate availability increases exogenous carbohydrate oxidation during endurance cycling. J Appl Physiol. 2010;109:126-34.

30. Rehrer NJ, Wagenmakers JM, Beckers EJ et al. Gastric emptying, absorption, and carbohydrate oxidation during prolonged exercise. J Appl Physiol. 1992;72(2):468-75.

31. Stocks B, Betts JA, McGawley K. Effects of carbohydrate dose and frequency on metabolism, gastrointestinal discomfort, and cross-country skiing performance. Scand $J$ Med Sci Sports. 2016;26:1100-8.

32. Hawley JA, Bosch AN, Weltan SM, Dennis SC, Noakes TD. Glucose kinetics during prolonged exercise in euglycaemic and hyperglycaemic subjects. Pflügers Arch. $1994 ; 426: 378-86$.

33. Rehrer NJ, Beckers F, Brouns F, Ten Hoor F, Saris WH. Exercise and training effects on gastric emptying of carbohydrate beverages. Med Sci Sports Exerc. 1989;21(5):540-9.

35. Wallis GA, Rowlands DS, Shaw C, Jentjens RL, Jeukendrup AE. Oxidation of combined ingestion of maltodextrins and fructose during exercise. Med Sci Sports Exerc. 2005;37(3):426-32. 

AJM. The effects of increasing exercise intensity on muscle fuel utilisation in humans. $J$ Physiol. 2001;536(1):295-304.

37. Joyner MJ, Coyle EF. Endurance exercise performance: the physiology of champions. J Physiol. 2008;586(1):35-44.

38. Maughan RM, Leiper JB, McGaw BA. Effects of exercise intensity on absorption of ingested fluids in man. Exp Physiol. 1990;75:419-21.

39. Rehrer NJ, Meijer GA. Biomechanical vibration of the abdominal region during running and bicycling. J Sports Med Phys Fitness. 1991;31(2):231-4. testing. Int J Sports Nutr Exerc Metab. 2010;20:87-103. 
465 Figure 1. Exogenous (a), total (b) and endogenous (c) carbohydrate oxidation rates during 466 exercise in CHO-20 and CHO-5. *denotes difference between trials, ${ }^{*}$ denotes increase from 467 baseline for both $\mathrm{CHO}-20$ and $\mathrm{CHO}-5$, all $P<0.05$. (a) time $\mathrm{x}$ trial interaction effect: $P=$ 468 0.045. (b) time effect: $P<0.0001$, trial effect: $P=0.461$, time x trial interaction effect: $P=$ 469 0.081. (c) time x trial interaction effect: $P=0.041$.

470 Figure 2. Serum glucose (a) and insulin (b) concentrations at rest and during exercise.

$471{ }^{\#}$ denotes increase from baseline for both CHO-20 and CHO-5, $P<0.05$. (a) time effect:

$472 P<0.0001$, trial effect: $P=0.938$, time $x$ trial interaction effect: $P=0.095$. (b) time effect: $P=$ 473 0.002, trial effect: $P=0.404$, time $x$ trial interaction effect: $P=0.361$.

474 Figure 3. Percentage plasma volume change from baseline "denotes increase/ decrease from 475 baseline for both $\mathrm{CHO}-20$ and CHO-5, all $P<0.05$. Time effect: $P=0.020$, trial effect: $P=$ 4760.356 , time $x$ trial interaction effect: $P=0.425$.

477 Figure 4. Reported subjective feelings for gastrointestinal comfort (a) and stomach 478 bloatedness (b). $0=$ very comfortable, $10=$ extreme discomfort. (a) time effect: $P<0.0001$, 479 trial effect: $P=0.830$, time $x$ trial interaction effect: $P=0.313$. (b) time effect: $P<0.0001$, 480 trial effect: $P=0.880$, time $x$ trial interaction effect: $P=0.126$. 
Table 1. Whole-body oxygen consumption, carbon dioxide production, respiratory exchange ratio (RER), total CHO and fat oxidation rates and exogenous and endogenous $\mathrm{CHO}$ oxidation rates during the steady-state exercise period (20-100 min). Exogenous CHO oxidation has also been shown for 20-60 and 60-100 min.

\begin{tabular}{|c|c|c|c|}
\hline & $\mathrm{CHO}-20$ & $\mathrm{CHO}-5$ & $P$ \\
\hline$\dot{\mathrm{VO}}_{2}\left(\mathrm{~L} \cdot \mathrm{min}^{-1}\right)$ & $3.16 \pm 0.37$ & $3.11 \pm 0.36$ & 0.188 \\
\hline$\dot{\mathrm{VCO}}{ }_{2}\left(\mathrm{~L} \cdot \mathrm{min}^{-1}\right)$ & $2.73 \pm 0.34$ & $2.72 \pm 0.33$ & 0.644 \\
\hline RER & $0.87 \pm 0.03$ & $0.87 \pm 0.03$ & 0.350 \\
\hline Total CHO oxidation $\left(\mathrm{g} \cdot \mathrm{min}^{-1}\right)$ & $2.15 \pm 0.47$ & $2.23 \pm 0.45$ & 0.412 \\
\hline Fat oxidation $\left(\mathrm{g} \cdot \mathrm{min}^{-1}\right)$ & $0.70 \pm 0.18$ & $0.65 \pm 0.15$ & 0.234 \\
\hline Exogenous $\mathrm{CHO}$ oxidation $\left(\mathrm{g} \cdot \mathrm{min}^{-1}\right)$ & $0.38 \pm 0.11$ & $0.31 \pm 0.11$ & 0.017 \\
\hline Endogenous $\mathrm{CHO}$ oxidation $\left(\mathrm{g} \cdot \mathrm{min}^{-1}\right)$ & $1.78 \pm 0.45$ & $1.92 \pm 0.40$ & 0.148 \\
\hline Exogenous contribution to total $\mathrm{CHO}$ oxidation (\%) & $17 \pm 5$ & $14 \pm 4$ & 0.022 \\
\hline Endogenous contribution to total $\mathrm{CHO}$ oxidation (\%) & $83 \pm 5$ & $86 \pm 4$ & 0.022 \\
\hline \multicolumn{4}{|l|}{ Early and late phase exogenous $\mathrm{CHO}$ oxidation rates } \\
\hline Exogenous $\mathrm{CHO}$ oxidation, $20-60 \mathrm{~min}\left(\mathrm{~g} \cdot \mathrm{min}^{-1}\right)$ & $0.21 \pm 0.09$ & $0.15 \pm 0.08$ & 0.047 \\
\hline Exogenous CHO oxidation, $60-100 \mathrm{~min}\left(\mathrm{~g} \cdot \mathrm{min}^{-1}\right)$ & $0.55 \pm 0.14$ & $0.47 \pm 0.15$ & 0.019 \\
\hline
\end{tabular}


Figure 1
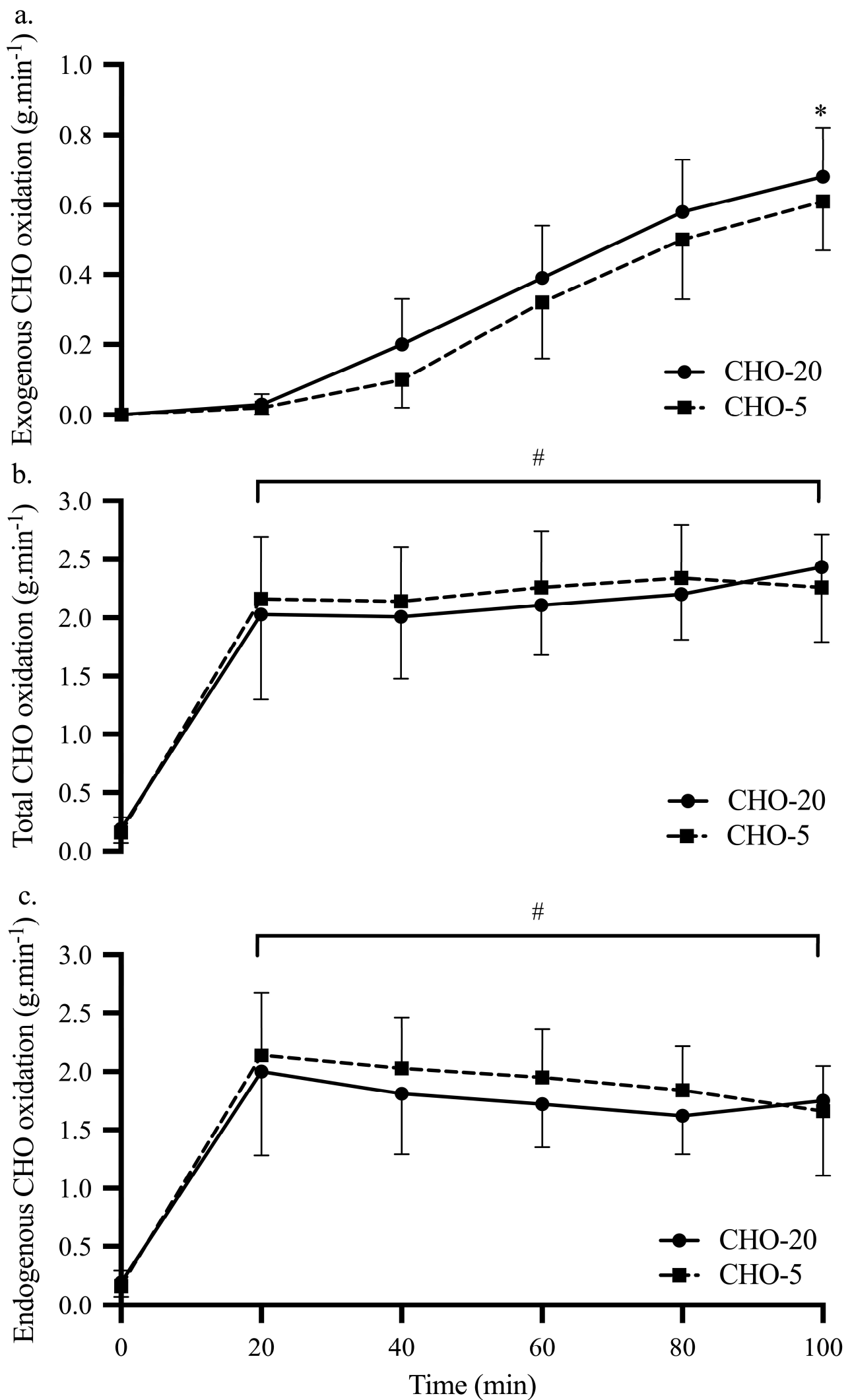
Figure 2

a.

\#
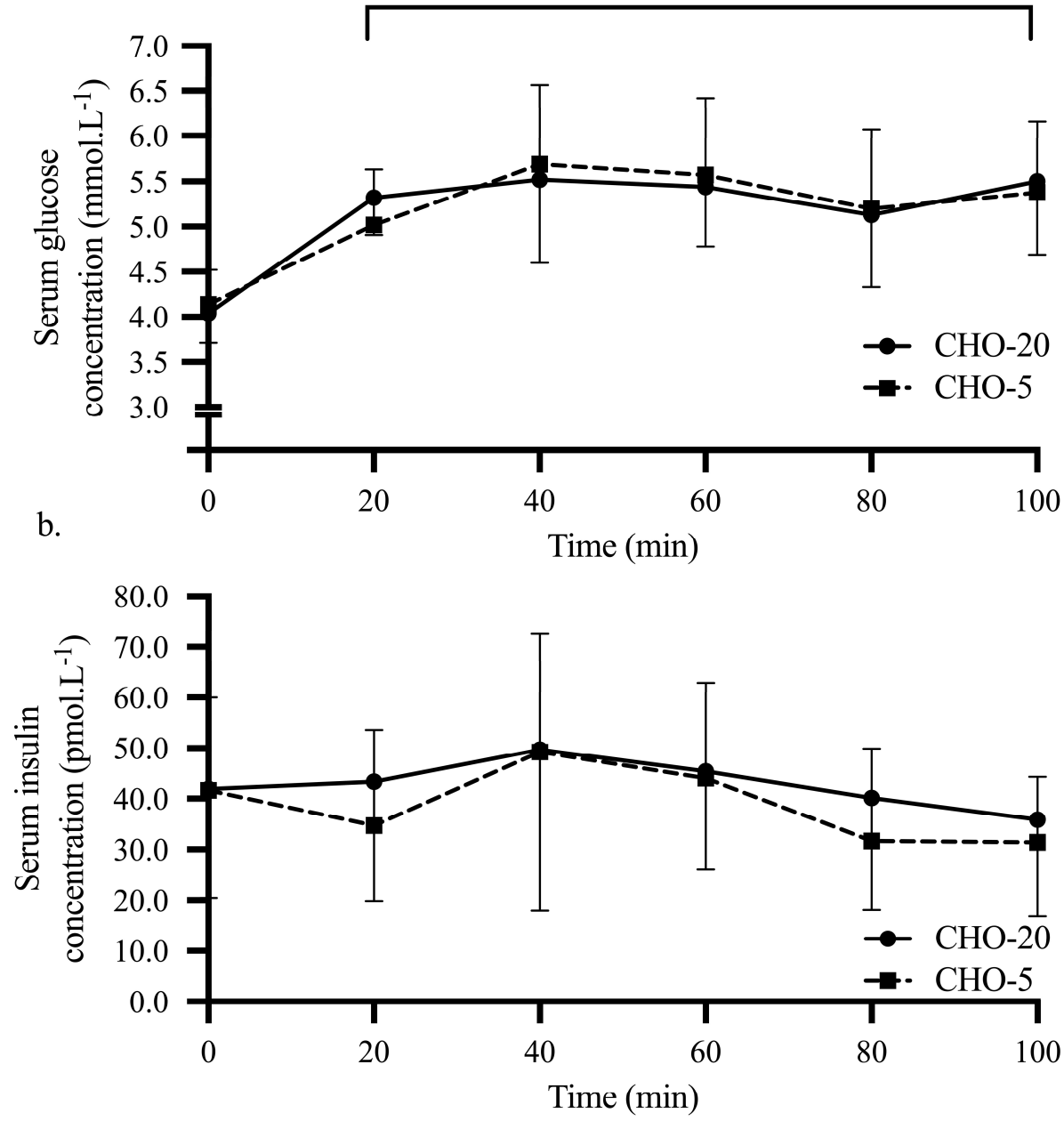
Figure 3

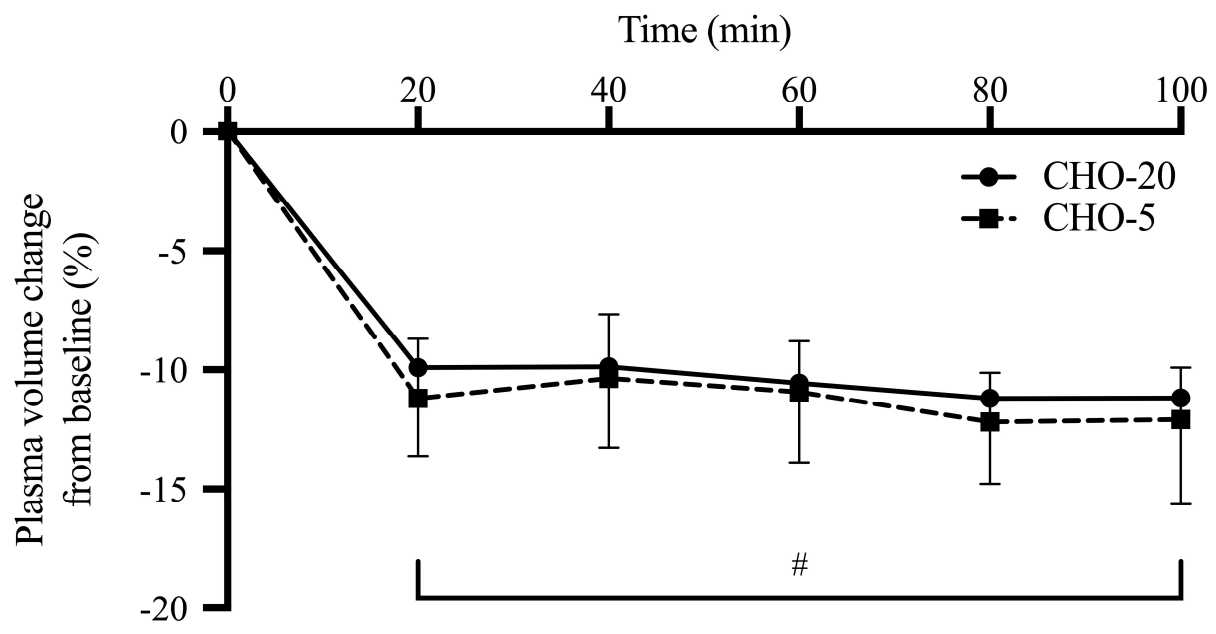

491

492

493

494 
Figure 4

496

a.
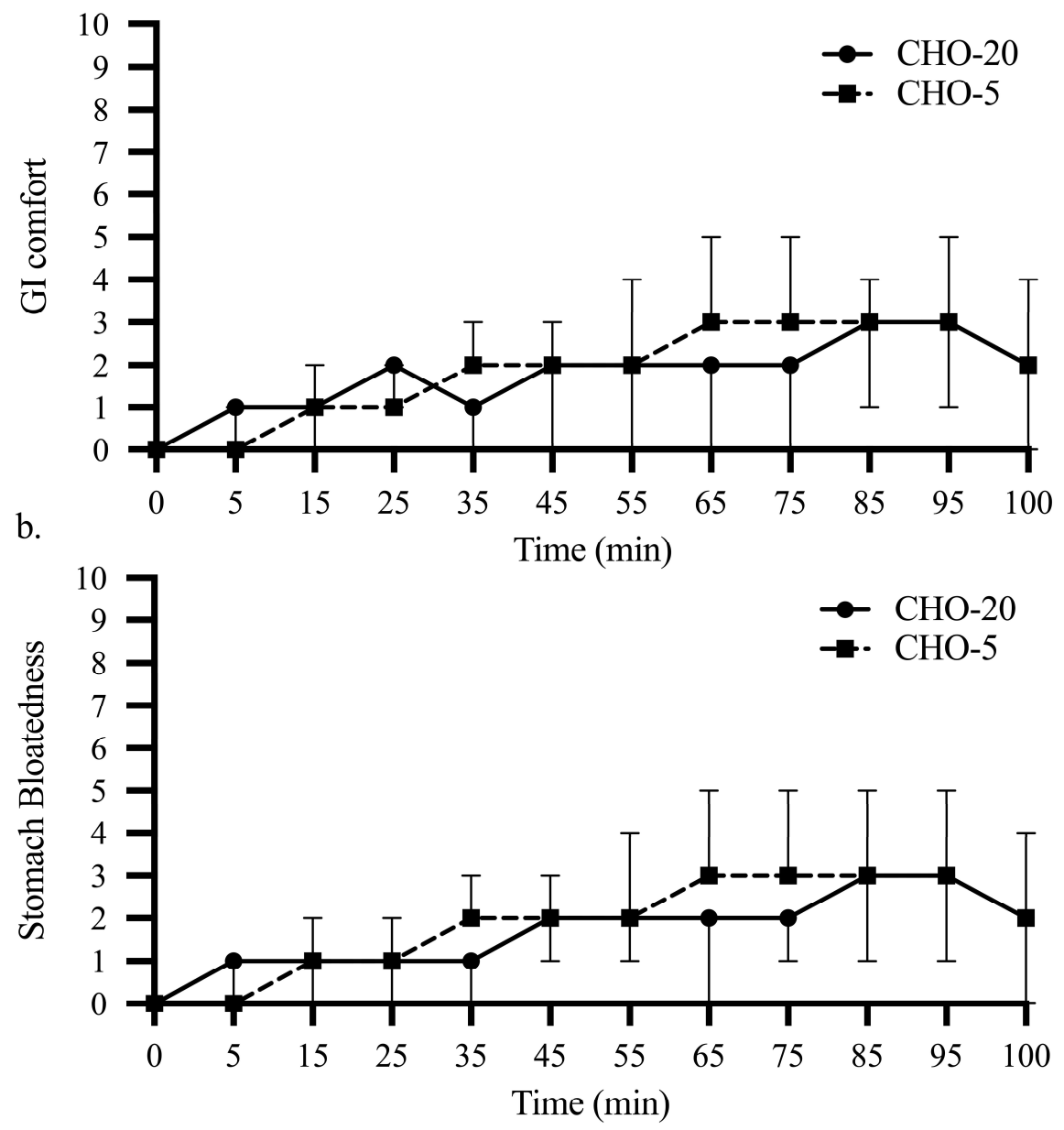